\title{
Parallel structure: A source of facilitation in sentence comprehension
}

\author{
LYN FRAZIER, LORI TAFT, TOM ROEPER, and CHARLES CLIFTON \\ University of Massachusetts, Amherst, Massachusetts
}

and

KATE EHRLICH

Yale University, New Haven, Connecticut

\begin{abstract}
Reading time for the second clause of a conjoined sentence was found to be faster when the clause was structurally similar to the first clause than when the clausal structures differed. This "parallel structure" effect was found for each of several types of structures, including active versus passive constructions, direct object versus sentential complement (minimal vs. nonminimal attachment), nonshifted versus shifted heavy noun phrase, agent versus theme, and animate versus inanimate noun phrase. The pervasiveness of the effect ruled out some hypotheses about its basis, including the hypothesis that it would occur only when a subject's just having processed a structture would affect how temporary ambiguities are resolved. Detailed analysis of the data suggested the existence of several distinct sources of the effect and provided indirect evidence that people typically compute both a surface structure and an S-structure representation of a sentence.
\end{abstract}

Readers and listeners strongly prefer coordinated elements of sentences to be parallel in structure. The interpretations assigned to sentences such as (1) and (2) indicate that this preference does not amount simply to an aesthetic judgment or stylistic convention. The ambiguous sentence

(1) Joshua hit the girl with a book and the boy with a bat

is easily parsed as a pair of conjoined sentences, in which the prepositional phrases modify the verb phrases, as indicated in (1a), or as a clause including an object consisting of conjoined noun phrases with prepositional phrase modifiers, as in (1b). However, as we trust will be clear to the reader, there seems to be little temptation to interpret this sentence as in (1c), in which the internal structures of the conjoined categories differ.

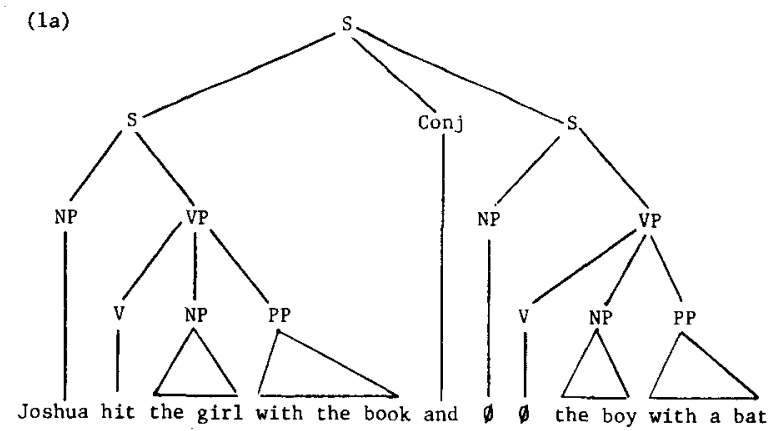

We would like to thank Lisa Letizio for assisting in collecting and analyzing the data reported here, Toni Borowsky, Peter Sells, and Betty Schlerman for helping to prepare the materials and to shape the ideas being tested, and Cynthia Connine for critically reading early drafts of this paper. This research was supported by NIMH Grant MH-35347 to Lyn Frazier and Charles Clifton. Please address reprint requests to Lyn Frazier, Department of Linguistics, University of Massachusetts, Amherst, MA 01003.
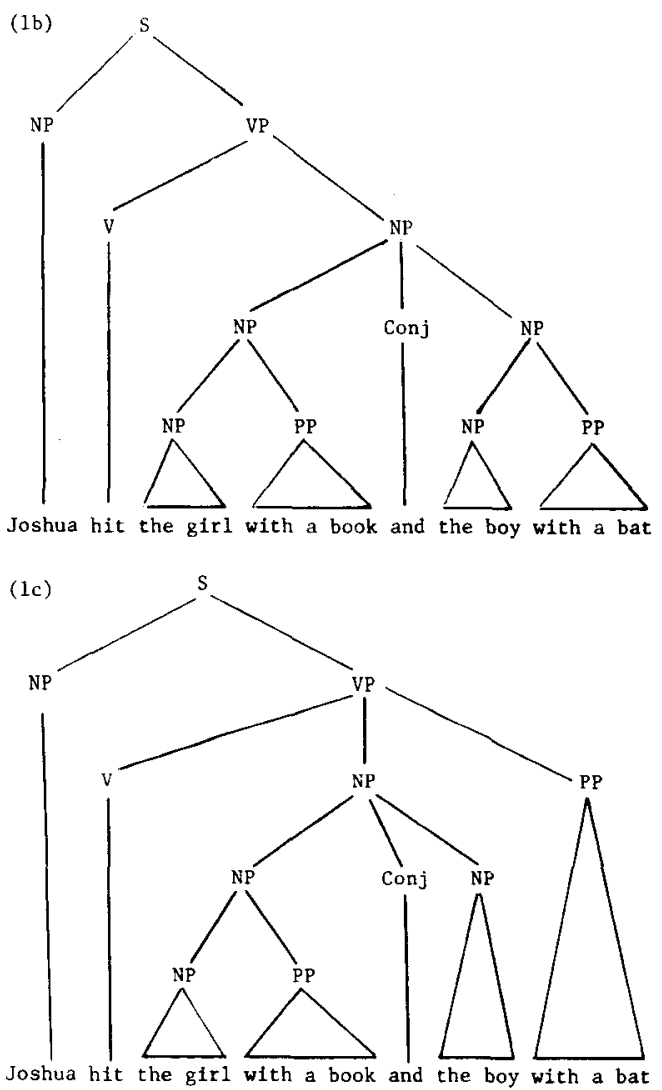

Exactly the same point may be illustrated by the interpretations assigned to the conjoined clauses in

(2) Joshua hit the girl with a book and Sammy hit the boy with a bat,

in which the parallel structures in (2a) and (2b) seem far 

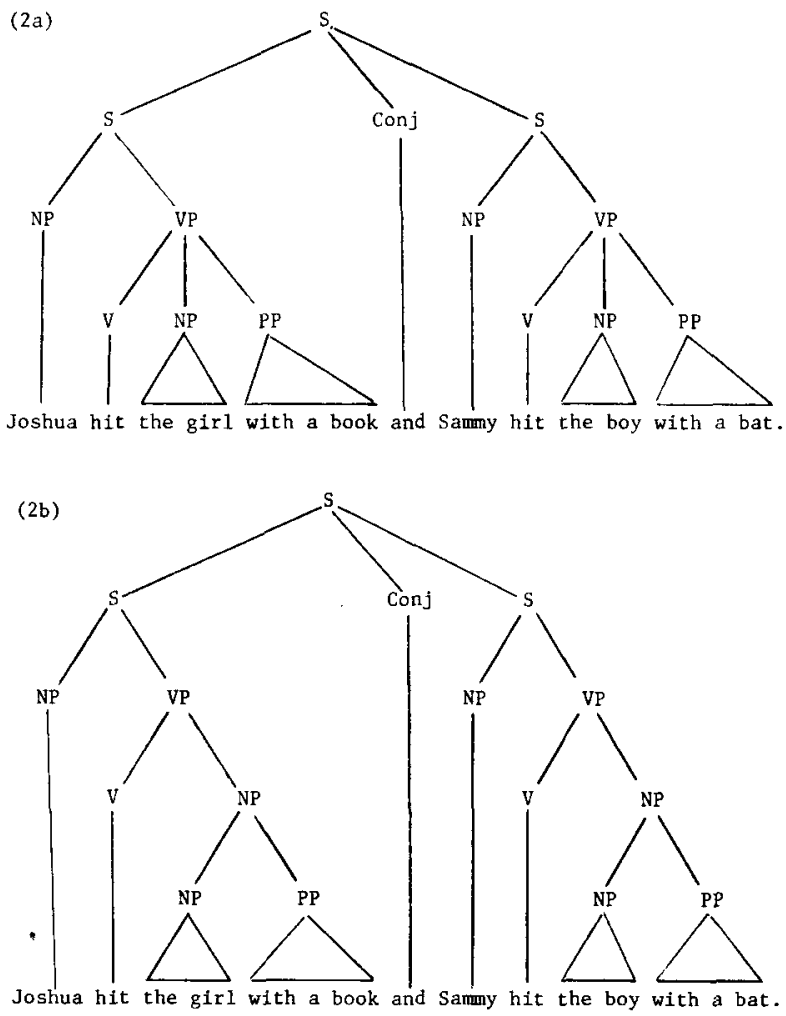

more likely to be computed than the nonparallel structures in (2c) and (2d).
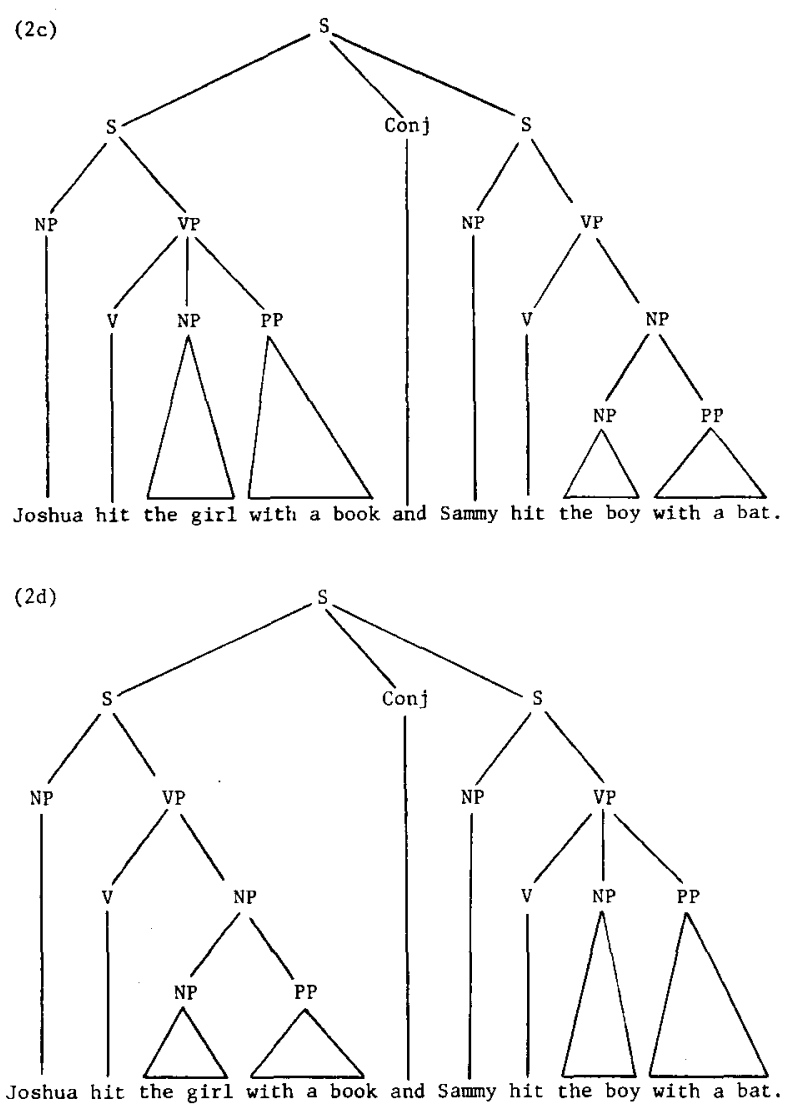

These observations suggest that the preference for parallel structures influences the actual parsing of sentences and is not simply an aesthetic judgment about the elegance of various sentence forms.

The observation that parallel coordinate structures are preferred to nonparallel ones is not novel, but it has received surprisingly little attention in the psycholinguistic literature. Perceptual set studies (Mehler \& Carey, 1968; D. Wilkenfield, personal communication, 1982) have shown that syntactic or prosodic structure assigned to a series of sentences may influence the analysis of a subsequent ambiguous sentence, and studies of the assignment of pronouns to antecedents (Sheldon, 1974; Solan, 1983) have indicated a preference for maintaining various types of parallelism in sentence interpretation. However, it is not known what aspects of the mental representation of sentences contribute to parallelism of structure or how parallelism of structure alters the processing of sentences.

The research to be reported here measures the time taken to read the second of two segments that are or are not parallel in various ways. We assume that faster reading time for the second of two parallel conjoined segments than for the second of two nonparallel segments indicates an influence-facilitatory or inhibitory, or both-of processing the first segment on the processing of the second. We will refer to this influence as the "parallel structure effect," or the "parallelism effect." Several possible mechanisms for the parallelism effect can be suggested. The most limited mechanism apparent to us claims that parallelism operates only in cases of temporary ambiguity (as was illustrated by our example sentences), and results from the strategy of choosing between two equally applicable rules at a point of temporary ambiguity by repeating a recently successful choice. A more inclusive mechanism, which still appeals to changes in the operations of creating structural representations of sentences, is that parsing routines that have just been executed are speeded in their use. A still more inclusive mechanism suggests that parallelism can have its immediate effects at stages of sentence comprehension in addition to stages involved in creating structural representations of the sentences. Parallelism of structure might increase the effective redundancy of syntactic information contained in the second element of a parallel structure. If this reduces the memory load imposed by the second element, thus freeing processing resources, then all stages of sentence comprehension could be speeded.

Whatever the details of the phenomenon and the mechanisms responsible for it, there appears to be a preference for parallel structures in human sentence comprehension. The pervasiveness of this preference suggests that it may reflect some basic aspects of the human comprehension system and that understanding its nature may reveal fundamental aspects of sentence comprehension and perhaps of human cognition in general. However, it may be that the preference for parallel structures is not completely pervasive, but holds only at some, not all, levels of grammatical representation. If so, the investigation of 
parallel structures might provide a useful technique for determining what levels of linguistic representation are constructed during comprehension and, perhaps, for identifying the time course of their construction.

In the present study, we tested five types of conjoined clauses to investigate a variety of possible sources of the parallelism effect. One possibility is that the only effect of structural parallelism is to alter the outcome of parsing decisions made at choice points (points of temporary ambiguity) in sentence parsing. To test this possibility, we contrasted unambiguous sentences (the active vs. passive sentences, designated " 1 " in Table 1) with sentences that are temporarily ambiguous [the sentences with direct objects vs. sentential complements (" 2 "' in Table 1), which we will refer to as "minimal attachment" vs. "nonminimal attachment"]. These latter minimal and nonminimal attachment sentences are temporarily ambiguous, in that the noun phrase following the verb, "all Tom's stories," can receive a simple direct object interpretation or an interpretation as the subject of a complement sentence. The former interpretation is correct for the minimal attachment sentences, for example, $(2 \mathrm{a})$ in Table 1 , and the latter for the nonminimal attachment sentences, for example, (2b) in Table 1. Readers have an initial preference for the former interpretation (Frazier, 1979; Frazier \& Rayner, 1982), because they avoid postulating potentially unnecessary structure, and the nonminimal attachment sentences have an extra $\mathrm{S}$ constituent in the matrix verb phrase. If parallelism of structure affects only the decisions made at points of temporary ambiguity, then effects of parallel structure should be seen only in the case of the minimal attachment and nonminimal attachment sentences. In Table 1, the second conjuncts of (2a) and (2b) should be read more quickly than the second conjuncts of (2c) and (2d). For instance, having just settled on the nonminimal attachment interpretation for the first conjunct of $(2 b)$, a reader should be biased toward the nonminimal attachment interpretation of its second segment, and thus should read it more quickly than the second segment of (2c). No difference would be expected for the active versus passive sentences in Table 1 , since these sentences have no relevant points of temporary ambiguity. Another possibility is that a parsing operation takes less time to perform if it has just been performed. Yet another is that parallelism in the ultimately correct structure of a sentence directly contributes to creating and interpreting the structural representation of a sentence. In either case, parallel structures should be easier to process than nonparallel structures, whether or not there is any ambiguity in the analysis of the sentence. Reading time for the second clause of the parallel sentences should be speeded, relative to the nonparallel sentences, for both the active/passive and the minimal/nonminimal attachment constructions.

The third structure tested used the "stylistic" rule of heavy noun phrase (heavy NP) shift, as illustrated in

Table 1

Example Sentences

Segment 1

1a. The tall gangster hit John

1b. John was hit by the tall gangster

1c. The tall gangster hit John

1d. John was hit by the tall gangster
Segment 2

Active/Passive

and the short thug hit Sam.

and Sam was hit by the short thug.

and Sam was hit by the short thug.

and the short thug hit Sam.

\section{Minimal Attachment/Nonminimal Attachment}

2a. Jim believed all Tom's stories

2b. Jim believed all Tom's stories were literally true

2c. Jim Believed all Tom's stories

$2 \mathrm{~d}$. Jim believed all Tom's stories were literally true

and Sue believed Jim's stories.

and Sue believed Jim's stories were fictitious. and Sue believed Jim's stories were fictitious. and Sue believed Jim's stories.

\section{Nonshifted/Shifted Heavy NP}

3a. Mary wrote a long note about her predicament to her mother. 3b. Mary wrote to her mother a long note about her predicament.

3c. Mary wrote a long note about her predicament to her mother.

$3 \mathrm{~d}$. Mary wrote to her mother a long note about her predicament.

and Sue wired a telegram requesting more money to her father. and Sue wired to her father a telegram requesting money. and Sue wired to her father a telegram requesting money. and Sue wired a telegram requesting more money to her father.

Agent/Theme

4a. Jack rolled down the hill

4b. The rock rolled down the hill

4c. Jack rolled down the hill

4d. The rock rolled down the hill

and George did too.

and the bucket did too.

and the bucket did too.

and George did too.

Animate/Inanimate

5a. John telephoned the doctor

5 b. John telephoned the library

5c. John telephoned the doctor

5d. John telephoned the library

Note-Within each sentence category, the first two example sentences exhibit parallel constructions, whereas the last two exhibit nonparallel constructions. The first segment alternates between the "less-marked" and the "more-marked" forms, whereas the second segment exhibits the "less-marked" form in the first and fourth examples and the "more-marked" form in the second and third. and his friend telephoned the lawyer. and his friend telephoned the museum. and his friend telephoned the museum. and his friend telephoned the lawyer. 
Table 1, sentences (3a)-(3d), to test yet another possibility concerning where and how parallelism operates. Heavy NP shift is a rule that moves certain long and complex noun phrases to a clause-final position, where they will not disrupt the processing of the clause. In a grammar of the structure proposed by Chomsky and Lasnik (1977), such stylistic rules apply to objects called Sstructures, which are the products of the phrase structure rules of the base plus the remaining few movement, adjunction, and substitution transformations. The stylistic rules, together with phonological rules and rules blocking unpermitted structures, produce surface structures; semantic rules, including rules of construal, apply to Sstructures to create logical form. The sentences in (3) all have the same S-structure, although their surface structures differ. The grammatical model upon which the distinction between S-structure and surface structure is based suggests that perceivers must recover an S-structure representation of a sentence in order to interpret it, but they may not have to recover the more superficial surface structure representation. For example, a reader confronted with a sentence containing a phrase moved by the stylistic rule of heavy NP shift may not have to incorporate that phrase into a surface structure representation in a linear position corresponding to its linear position in the input lexical string. He or she may be able to incorporate the phrase directly into its appropriate position in the S-structure, ready for semantic interpretation. If in fact the sentence parsing mechanism never computes a surface structure, but immediately undoes the effect of stylistic rules, and if it is only parallelism of representation, not facilitation of parsing procedures, that contributes to the parallel structure effect, then there should be no difference in reading time between the second conjuncts of the sentences in (3). ${ }^{1}$ If, on the other hand, surface structure representations are constructed, and if they are relevant to the effect of structural parallelism, then the second conjuncts of the parallel sentences ( $3 a$ and $3 b$ ) should be read more quickly than the second conjuncts of the nonparallel sentences ( $3 \mathrm{c}$ and $3 \mathrm{~d}$ ).

The last set of constructions investigated are illustrated in (4) and (5) of Table 1. The structures in (4) are parallel or nonparallel with respect to the possible thematic role of the subject noun phrase (Jackendoff, 1972). In (4a), Jack acts as both agent and theme of roll (cf. Jack rolled himself down the hill.). In (4b), the rock is simply the theme of roll. Thematic role is not a part of the constituent structure of a sentence, so if only constituent structure is relevant to structural parallelism, or if only decisions about constituent structure are facilitated by parallelism, then no effect of parallel thematic roles should be observed in (4). However, in several analyses, thematic role is a part of the structural descriptions of sentences at some level. ${ }^{2}$ If this structural description is constructed in normal sentence comprehension, and if the parallelism effect is not limited to cases of temporary ambiguity, then the effect should be observed with the sentences of (4).
The sentences of (5) were included as controls for the animate/inanimate dimension that is confounded with agent/theme in (4). These sentences included animate or inanimate NPs in nonagent position (e.g., as a second object or as a theme in syntactic subject position). If thematic role, but not animacy per se, is relevant to structural parallelism, then a parallel structure effect should be observed in (4) but not in (5). If animacy per se is relevant to structural parallelism, then a parallel structure effect would be expected for both (4) and (5).

\section{METHOD}

\section{Materials}

Sixty experimental sentences (examples of which appear in Table 1, and all of which appear in the Appendix) were constructed. Each consisted of two one- or two-clause conjoined segments. In 12 sentences, the two conjoined segments were active or passive. In 12 others, the two segments' verbs either each had a direct object (minimal attachment) or a sentence complement (nonminimal attachment). In 12 more, the two conjoined segments each had a double-object verb, such that the direct object immediately followed the verb (nonshifted) or occurred only after the indirect object (shifted). These three groups of 12 sentences will be referred to as the "syntactic" constructions, since the two segments contrasted in a syntactically describable way. In a fourth group of 12 sentences, the two segments had animate subjects that should be interpreted as agents or had inarimate subjects that could only be interpreted as themes. A fifth group of 12 sentences served as a control for animacy in having either animate or inanimate nouns in nonagentive roles (either subject or object position). These last two groups of 12 sentences will be called the "animacy" conditions. Questions were constructed for 45 of these 60 sentences (e.g., the sentence "John telephoned the doctor and his friend telephoned the museum" was followed by the question "Did John's friend telephone the doctor?"). Some questions were designed to require close reading and involved changes in thematic roles of entities mentioned in the sentence, substitutions of closely related words for one another, and the like. To prevent the task from exhausting the subjects, questions followed only some of the sentences.

Four forms of each of these 60 experimental sentences were written. In two forms (the "parallel" forms), the first and the second segment appeared in the same construction (e.g., both passive or both active). In the other two ("nonparallel") forms, the first and the second segment contrasted on the relevant linguistic dimension (e.g., the first segment might have heavy NP shift, and the second not). Thus, the experimental sentences can be seen as varying in three factors: (1) sentence construction (active vs. passive, minimal attachment vs. nonminimal attachment, heavy NP nonshift vs. shift, agent vs. theme, animate vs. inanimate object); (2) parallel versus nonparallel construction; and (3) form (whether a given segment was the more- or the lessmarked sentence construction, where active, minimal attachment, and nonshifted are assumed to be less marked (i.e., more elementary) for processing reasons, and the agentive and animate forms are assumed to be less marked for general cognitive reasons. Experimental evidence shows that minimal attachment sentences are perceptually less complex than nonminimal attachment sentences, and that in isolation or in contexts that do not specifically license them, passives are more complex than actives (Davison \& Lutz, 1981; Frazier, 1979; Frazier \& Rayner, 1982). Both in terms of their linguistic description and intuitively, sentences with unshifted NPs are less marked than those with shifted NPs. Several experimental studies have shown that agents and animate nouns enjoy a special cognitive status; certainly, in language acquisition they seem to be given a special priority (cf. Hakuta, 1982), and their special status is reflected in many genetically diverse languages (cf. Comrie, 1979).

An additional 52 filler sentences were constructed, 23 of which had questions. Each filler sentence was divided into two segments, either 
coordinate clauses or clauses in a main-subordinate relationship to each other. No filler sentences had the clear parallelism (or violation of parallelism) present in the 60 experimental sentences. Six more sen'tences, 4 with questions, were constructed as practice materials.

\section{Subjects}

Seventy-two undergraduate volunteers from psychology courses at the University of Massachusetts served as subjects. One additional subject was rejected for having excessively long reading times. Each was tested individually in a single .5 -h session, combined (for some subjects) with a second experiment on auditory sentence comprehension.

\section{Procedure}

After receiving instructions, the subjects were tested in a single block of 6 practice trials and then on the 112 trials of the experiment. Each trial began with the message "Press Center Button to See Sentence" presented at the center of a computer-controlled video screen. When the subject pressed the central button on a response console, the first segment of a sentence appeared centered on the screen. This segment remained until the subject pressed the response button, at which time it was replaced by the second segment of the sentence. Depressing the button removed this segment, which was replaced immediately by a question about the sentence (for the 68 sentences that had questions) or by the message to initiate the next trial. The yes/no question was answered by pressing one of two response buttons to the right and left of the central button. The subject was given an opportunity to rest after every 24 trials.

Each subject was instructed to read each segment as rapidly as possible, while maintaining the ability to answer questions very quickly and accurately. Reading times for each segment, together with questionanswering time and accuracy, were recorded.

Eighteen subjects were assigned to each of four counterbalancing conditions, designed such that each experimental sentence occurred equally often in each of the four experimental conditions (parallel vs. nonparallel $\times$ less-marked vs. more-marked form), and such that each subject received equal numbers of sentences of each construction in each experimental condition. A separate randomization of the 112 trials was generated for each subject.

\section{RESULTS}

Mean reading times per word for the sentences in each experimental condition were calculated for each subject and for each sentence. The reaction time for each sentence segment was divided by the number of words in that segment, to yield a measure of mean reading time per word. ${ }^{3}$ In calculating these means, trials on which a subject answered a question erroneously were eliminated. Errors occurred on $17.6 \%$ of the trials on which questions were presented. Error rate differed by no more than eight percentage points within any subset of sentences and did not seem to be related to reading times (see Table 2). Furthermore, including trials on which errors were made did not change the pattern of results, but did increase error variance somewhat. Trials on which the mean time per word was over $1 \mathrm{sec} /$ word were then eliminated, resulting in a loss of $3.9 \%$ of the trials. Eighty-seven percent of these long reading times came from the minimal and nonminimal attachment sentences, reflecting their temporary ambiguity and their resulting ability to mislead subjects. These long times were equally distributed between minimal and nonminimal attachment sentences.

Separate analyses of variance were conducted on the first three ("syntax") sentence constructions and on the last two ("animacy") constructions. Preliminary analyses
Table 2

Mean Reading Time Per Word (in Milliseconds) and Question-Answering Error Percentages, Second Segment

\begin{tabular}{|c|c|c|c|}
\hline \multirow[t]{2}{*}{$\begin{array}{c}\text { Form of } \\
\text { Second Segment }\end{array}$} & \multicolumn{2}{|c|}{ Form of First Segment } & \multirow[t]{2}{*}{$\begin{array}{c}\text { Size of } \\
\text { Parallelism } \\
\text { Effect (in msec) }\end{array}$} \\
\hline & Active & Passive & \\
\hline Active & $282(10 \%)$ & $315(18 \%)$ & 33 \\
\hline \multirow[t]{2}{*}{ Passive } & $248(13 \%)$ & $236(11 \%)$ & 12 \\
\hline & $\begin{array}{c}\text { Minimal } \\
\text { Attachment }\end{array}$ & $\begin{array}{l}\text { Nonminimal } \\
\text { Attachment }\end{array}$ & \\
\hline Minimal Attachment & $278(21 \%)$ & $283(25 \%)$ & 5 \\
\hline \multirow[t]{2}{*}{ Nonminimal Attachment } & $298(22 \%)$ & $275(22 \%)$ & 23 \\
\hline & Nonshifted & Shifted & \\
\hline Nonshifted & $260(17 \%)$ & $260(15 \%)$ & 0 \\
\hline \multirow[t]{2}{*}{ Shifted } & $277(15 \%)$ & $254(22 \%)$ & 23 \\
\hline & Agent & Theme & \\
\hline \multirow{3}{*}{$\begin{array}{l}\text { Agent } \\
\text { Theme }\end{array}$} & $245(4 \%)$ & $261(4 \%)$ & 16 \\
\hline & $263(6 \%)$ & $249(5 \%)$ & 14 \\
\hline & Animate & Inanimate & \\
\hline Animate & $266(13 \%)$ & $281(12 \%)$ & 15 \\
\hline Inanimate & $267(10 \%)$ & $257(13 \%)$ & 10 \\
\hline
\end{tabular}

of variance were conducted using data from both the first and the second segments of each sentence. Although reading times were significantly longer $\left(p<.01\right.$ by min $\left.F^{\prime}\right)$ for the first segments than for second segments ( $305 \mathrm{vs.}$ $272 \mathrm{msec} /$ word in the syntax analysis; $321 \mathrm{vs.}$ $261 \mathrm{msec} /$ word in the animacy analysis), no effects of the parallelism manipulation on first-segment reading times were found in either analysis, and the segments $x$ parallelism interactions that justify examining the secondsegment data by themselves were significant in both analyses.

The mean reading times per word in the second segments appear in Table 2 . The analysis of the syntax constructions will be discussed first. The factors in the analysis were sentence construction (passive/active, nonminimal/minimal attachment, nonshifted/shifted), parallel/nonparallel form, and tested sentence markedness (more-marked or less-marked version of a construction). Separate analyses were conducted to permit generalization over subjects and over items. Subjects read second segments faster when the segments were parallel in structure to the first segments than when they were nonparallel $\left[F_{1}(1,71)=13.72, p<.001\right.$, and $F_{2}(1,33)=6.96$, $p<.02]$. The effects of markedness and the sentence construction $\times$ markedness interaction were also significant in both analyses $\left[F_{1}(1,71)=15.04, p<.001\right.$, and $F_{2}(1,33)=4.61, p<.05$, in the former case; $F_{1}(2,142)$ $=33.96, \mathrm{p}<.001$, and $\mathrm{F}_{2}(2,33)=7.18, \mathrm{p}<.01$, in the latter]. However, as was argued in Footnote 1, effects of markedness cannot be interpreted in the present experiment, because they are confounded with segment length. The only other effect to reach or approach significance in both analyses was a most intriguing interac- 
tion among sentence construction, markedness, and parallelism $\left[\mathrm{F}_{1}(2,142)=3.95, \mathrm{p}<.03 ; \mathrm{F}_{2}(2,33)=\right.$ $2.57, .05<\mathrm{p}<.10]$. This interaction can be seen in the right-hand column of Table 2 , and seems to be due to a distinct pattern of asymmetries in the parallelism effect across the various constructions. Individual contrasts indicated that the effect of parallelism was significant for active second segments, nonminimal attachment second segments, and heavy NP shifted second segments ( $\mathrm{p}<.05$ in both subjects and items analyses, except in the case of the items analysis for nonminimal attachment second sentences, in which the level of significance was only .10). The parallelism effect did not approach significance for passive, minimal attachment, or nonshifted second segments in either analysis. However, simple tests of the interaction between markedness and parallelism for each construction type resulted in significance levels of only .10 in the subjects analysis and in nonsignificance in the items analysis. Although the experiment was not designed with sufficient power to investigate the interaction among construction type, markedness, and parallelism in any conclusive fashion, the apparent interaction is of enough theoretical interest that we will speculate about its basis in the Discussion.

Subjects also read parallel second segments faster than nonparallel second segments for the animacy sentences (agent/theme and animate/inanimate) $\left[F_{1}(1,71)=13.21\right.$, $\mathrm{p}<.001$, and $\left.F_{2}(1,22)=9.07, p<.006\right]$. No other effect approached significance in both the subjects and the items analysis, and the theoretically crucial interaction between sentence construction and parallelism was thoroughly nonsignificant $\left[F_{1}(1,71)=0.09\right.$ and $F_{2}(1,22)$ $=0.01]$. Although reading times appeared to be slower for the animate/inanimate segments than for the agent/theme segments in the subjects analysis $\left[F_{1}(1,71)\right.$ $=11.35, \mathrm{p}<.002]$, the difference must have been due to a deviant subset of sentences, since it did not reach significance in the items analysis $\left[\mathrm{F}_{2}(1,22)=2.27\right.$, $\mathrm{p}>.10]$.

\section{DISCUSSION}

The most striking aspect of these findings is the pervasiveness of the basic parallel structure effect. Effects of parallel structure were found within each construction type tested. This generality indicates that the first mechanism we considered, namely, that parallel structure effects would be found in cases in which a preceding structure could bias the decision at a point of temporary ambiguity, is not the only source of the parallelism effect. Had such a mechanism been the only one, we would have found a parallelism effect only in the minimal versus nonminimal attachment sentences, since they were the only ones with a clear temporary ambiguity. Even more generally, our findings rule out the very plausible hypothesis that parallel structure effects would be due only to a speeding up of, or change in the priority of, particular parsing routines. If that hypothesis had been correct, then facilitation would have been expected only when the structure involved had some bearing on an actual parsing decision (e.g., creation of phrase structure, assignment of syntactic role), but not when the animacy of noun phrases was the only basis of parallelism.

One possible conclusion to draw from the data is that, when a person has just completed constructing a representation of part of a sentence, fewer cognitive demands will be made by constructing and storing the representation of the remaining part of the sentence to the extent that the representations share common features. The features of the representations may be primed, and thus made more quickly available, or parallelism between the representations could be noted and used to reduce the effective memory demands, speeding all aspects of processing. An important question under this conclusion is to determine whether any linguistic characteristics of sentences fail to serve as the basis of a parallelism effect. Identifying such a characteristic would indicate a limit on what is contained in the mental representation of a sentence.

An alternative conclusion to draw from the data is that several distinct mechanisms or sources operate to create the parallel structure effect. The interaction among sentence construction, sentence form, and parallelism (significant by subjects, marginally significant by items) gives some credence to this conclusion. Although the experiment was not specifically designed to study this interaction, as indicated earlier, the interaction is of sufficient potential importance to warrant devoting some discussion to its possible interpretations. Consider first the minimal/nonminimal attachment constructions. A significant parallelism effect was observed for the marked nonminimal attachment sentence form (e.g., "The spy saw the man with the umbrella poison Harold"'), but little or no effect was observed for the unmarked form ("The spy saw the man with the umbrella"). Normally, comprehension of a nonminimal attachment sentence is hampered by the reader's tendency to first assign a minimal attachment analysis to it, with the consequent need to reanalyze the sentence (Frazier, 1979; Frazier \& Rayner, 1982). The parallelism effect may operate in the minimal/nonminimal attachment sentences by preventing such "garden paths" in nonminimal attachment clauses, while not inducing them in minimal attachment clauses. Having just read, misanalyzed, and reanalyzed a nonminimal attachment clause as the first of two apparently parallel conjuncts, a reader may delay making a decision at the point of structural ambiguity in the second conjunct or may construct both possible analyses of the ambiguous segment rather than accepting the first analysis he or she arrives at (Frazier \& Fodor, 1978). In either case, the reader will not be garden-pathed by a nonminimal attachment clause that follows another such clause in a coordinate construction. Its difficulty will therefore be less than when it follows a minimal attachment clause. (This reduction in difficulty would be partly offset by costs of delaying or duplicating analyses. However, we assume that these are minimal, when contrasted with the costs of 
garden paths.) Effects on minimal attachment second conjuncts will be small, since delaying or duplicating analyses will not induce garden paths in them.

Consider next the heavy NP shift sentences, for which a parallelism effect was found only for the marked shifted second segments. This effect cannot readily be explained in the same fashion as the minimal attachment sentences. There is no temporary ambiguity in the syntactic analysis of these sentences, so no misanalysis could have been prevented by the prior occurrence of the marked sentence form. However, the asymmetry in the size of the parallelism effect for these sentences is naturally explained on the assumption that the processor, to shortcut its processing of the second conjunct, uses the information that coordinate structures tend to be parallel. When the processor has just encountered a clause with a shifted noun phrase (e.g., "Reagan sent to his supporters many pleas for funds") and has "returned" it to its unshifted (S-structure) position ("Reagan sent many pleas for funds to to his supporters"), the processor apparently need not bother constructing a surface structure representation of the second conjunct. Instead, it may construct an S-structure with the shifted noun phrase in its appropriate S-structure position immediately upon encountering the shifted noun phrase in the second conjunct. When an unshifted noun phrase occurs in the second conjunct, it will make no difference at all whether the preceding clause concontained a shifted or unshifted noun phrase, since the processor will be left with exactly the same representation (equivalent to the $S$ structure configuration) in either case.

In contrast to the attachment and heavy NP sentences, the active versus passive sentences showed a significant difference between parallel and nonparallel conditions only when the unmarked (active) form occurred in the second conjunct. We think that the complexity of the nonparallel sentences with a passive clause followed by an active clause is due to the discourse role of the passive (cf. Anisfeld \& Klenbort, 1973). The passive sentence provides an explicit syntactic marker of the topic (Davison, 1984; Davison \& Lutz, 1981), whereas an active sentence does not. The passive, therefore, will most likely be used in a discourse context in which the theme (or conceptual object) of the sentence is the topic of the discourse. Since our active/passive sentences have a conceptual parallelism, any discourse context that licenses the speaker to mark the topic of the first conjunct explicitly will likely be one that licenses the topic of the second conjunct to be marked also. On the other hand, an initial active segment forces no commitment about the topic of conversation, thus leaving the voice of the second segment unconstrained.

Although this specific suggestion is hardly more than a restatement of the facts, a generalization of it is possible. Nonparallel coordinate structures containing explicitly topic-marking structures should generally have the unmarked construction preceding the marked construction, rather than vice versa. For example, (3a) A fly was in my soup and there was an ant crawling in Harry's potato salad.

should be preferred to

(3b) There was a fly in my soup and an ant was crawling in Harry's potato salad.

if existential there sentences are constructions that explicitly mark topics. Our intuitions indicate that this is so.

We cannot fully resolve whether the parallelism effect we have identified reflects a totally general increase in the availability of all relevant aspects of the structural representations of sentences or (additionally or alternatively) reflects a variety of quite distinct and specific mechanisms. The former interpretation suggests interesting ways of determining what aspects of sentences are contained in their mental representations. The latter interpretation is attractive because it provides a means for examining detailed questions about sentence processing mechanisms, permitting us to distinguish between effects of the processor's decision procedures and effects due directly to the representations that have been constructed. It also promises to reveal subtle effects of the order of topic-marking and topic-free constructions. Under either interpretation, the observed parallelism effects provide some new information about the processes of sentence comprehension-for example, that surface structures as well as S-structures are typically created in the process of comprehending a sentence-and they provide a new method for probing these processes.

\section{REFERENCES}

ANISFELD, M., \& KLENBORT, I. (1973). On the functions of structural paraphrase: The view from the passive voice. Psychological Bulletin, 79, 117-126.

ChIERCHIA, G. (1983, February). Outline of a semantic theory of (obligatory) control. Paper presented at the West Coast Conference on Formal Linguistics, II, Los Angeles.

Сномsкy, N. (1981). Lectures on government and binding: The Pisa lectures. Dordrecht, Holland: Foris.

СномSKY, N., \& LASNIK, H. (1977). Filters and control. Linguistic Inquiry, 8, 425-504.

Comrie, B. (1979). Language universals and language typology. Chicago: University of Chicago Press.

DAvison, A. (1984). On the function and definition of "sentence topic" in sentence processing. In D. Dowty, L. Kartunnen, \& A. Zwicky (Eds.), Syntactic theory and how people parse sentences. Cambridge: Cambridge University Press.

Davison, A., \& LUTz, R. (1981). Measurement of syntactic complexity relative to context. Unpublished manuscript, University of Ilinois (Champaign-Urbana).

Frazier, L. (1979). On comprehending sentences: Syntactic parsing strategies. Bloomington, IN: Indiana University Linguistics Club.

FRAZIER, L. \& FODOR, J. D. (1978). The sausage machine: A new parsing model. Cognition, 6, 291-326.

FRAZIER, L., \& RAYNER, K. (1982). Making and correcting errors during sentence comprehension: Eye movements in the analysis of structurally ambiguous sentences. Cognitive Psychology, 14, 178-210.

HAKUTA, K. (1982). Interaction between particles and word order in the comprehension and production of simple sentences in Japanese children. Developmental Psychology, 18, 62-76. 
JACKENDOFF, R. (1972). Semantic interpretation in generative grammar. Cambridge, MA: MIT Press.

Mehler, J., \& CAREY, P. (1968). The interaction of veracity and syntax in the processing of sentences. Perception \& Psychophysics, 3, 109-111.

SHELDON, A. (1974). The acquisition of relative clauses in English. Bloomington, IN: Indiana University Linguistics Club.

Solan, L. (1983). Pronominal reference: Child language and the theory of grammar. Dordrecht, Holland: Reidel.

\section{NOTES}

1. It is possible to analyze some of the heavy NP shift sentences we used as temporarily ambiguous, between a transitive and an intransitive reading of the verb (as in "Mary wrote to her mother a long note . . ."). However, this is not a temporary ambiguity whose resolution could be affected by the form of the first conjunct used in our sentences, since in all cases, they contained only transitive verbs.

2. The theta criterion proposed by Chomsky (1981) claims that only a single thematic role may be assigned to each argument of a verb. In this framework, the intransitive verb roll would syntactically assign only the role of theme to its subject; the fact that Jack in (4a) of Table 1 also serves as agent would involve a pragmatic inference. Alternatively, one might weaken the theta criterion to specify that a single thematic role may not be assigned to more than one argument (cf. Chierchia,
1983). Until this issue is resolved, the level of grammatical representation at which the sentences in (4c) and (4d) involve nonparallel thematic representations will remain indeterminate.

3. As pointed out by a reviewer, the mean-reading-time-per-word measure overestimates true reading speed for long segments, because each segment has associated with it some constant time for registration, buttonpressing, etc., and because our long segments tend to have more short function words in them than our short segments do. Total reading time per segment, on the other hand, underestimates reading speed for long segments, simply because these segments do have more words in them. Some intermediate measure of the relative difficulty of reading our different sentence constructions would be desirable. However, the obvious candidate, the deviations from reading times predicted as a linear function of sentence length, requires making the assumption that the effects of our parallelism manipulation are additive with sentence length, which is clearly not justified.

The only consequence of this problem is that we cannot directly compare reading speeds for constructions of different lengths, for example, active and passive or minimal and nonminimal attachment. Since the purpose of our experiment was to compare the reading speeds for a single segment when it followed two different kinds of segments, this problem is immaterial. Nonetheless, we did analyses on total reading times as well as on reading times per word, and aside from the finding of significantly longer reading times for passive than for active segments $(2,042$ vs. $1,863 \mathrm{msec})$ and for nominimal than for minimal attachment segments $(2,894$ vs. $2,399 \mathrm{msec})$, the results were completely congruent with the analyses reported.

\section{Appendix}

Sentences Used in the Experiment

John was hit by the tall gangster|The tall gangster hit John\#and Sam was hit by the short thug.|and the short thug hit Sam.\#(1 1

Peter was visited by his mother|His mother visited Peter\#and Mary was visited by her father.|and her father visited Mary.\#(1 2

The princess was kissed by the prince|The prince kissed the princess\#and the queen was hugged by the king. land the king hugged the queen.\#(1 3

The script was written by a best-selling author|A best-selling author wrote the script\#and the music was composed by a famous composer.|and a famous composer composed the music.\#(1 4

The villain was hurt by the falling scenery|The falling scenery hurt the villain\#and the dancers were disturbed by all the noise|and all the noise disturbed the dancers. $\#(15$

The film was seen by millions|Millions saw the film\#and the book was sold by many book stores. |and many book stores sold the book.\#(1 6

The father was sent a note by the teacher|The teacher sent the father a note\#and the boy was whipped by the headmaster.|and the headmaster whipped the boy.\#(1 7

The dining room was painted by John|John painted the dining room\#and the living room was painted by Joanna.|and Joanna painted the living room.\#(18

The main course was cooked by the adults|The adults cooked the main courseffand the dessert was prepared by the kids.|and the kids prepared the dessert.\#(19

The restaurant was opened by a rich Texan|A rich Texan opened the restaurant\#and the adjoining book store was opened by a local hippie.|and a local hippie opened the adjoining book store.\#(1 10

The book was written by a famous author|A famous author wrote the book\#and the screenplay was written by an obscure English teacher.|and an obscure English teacher wrote the screenplay. \#(1 11

The car body was designed by the head engineer|The head engineer designed the car body\#and the engine was designed by his assistant.|and his assistant designed the engine.\#(1 12

John attributed to arson the fire that started in the barn|John attributed the fire that started in the barn to arson\#and Sue attributed to sabotage the bombing of the mayor's garage. |and Sue attributed the bombing of the mayor's garage to sabotage.\#(2 13

My sister contributed to a bake sale a huge meringue pie|My sister contributed a huge meringue pie to a bake sale\#and my brother contributed to a car wash two sponges and pails. land my brother contributed two sponges and pails to a car wash.\#(2 14

John gave to his friends lots of copies of old cartoons|John gave lots of copies of old cartoons to his friends\#and Steve sent to his pals some old issues of Science. land Steve sent some old issues of Science to his pals.\#(2 15

Mary wrote to her mother a long note about her predicament|Mary wrote a long note about her predicament to her mother\#and Sue wired to her father a telegram requesting more money.|and Sue wired a telegram requesting more money to her father.\#(2 16

Paul told to his teacher some tale about why he was late|Paul told some tale about why he was late to his teacher\#and Sue told to her teacher a lie about why she missed the test.|and Sue told a lie about why she missed the test to her teacher.\#(2 17 
A soldier showed to his friends the wounds he received in battle $\mid$ A soldier showed the wounds he received in battle to his friendsłand they displayed to the kids all the medals he'd won. and they displayed all the medals he'd won to the kids.\#(2 18

John bought for his kids as many pancakes as they could eat|John bought as many pancakes as they could eat for his kids\#and Mary made her son the largest omelette he'd ever seen.|and Mary made the largest omelette he'd ever seen for her son. \#(2 19

Tom made for the piazza a huge marble statue of the pope|Tom made a huge statue of the pope for the piazza\#and Lisa designed for the entrance an imposing columned staircase.|and Lisa designed an imposing columned staircase for the entrance.\#(2 20

Mary hid in the closet as many gifts as she could fit|Mary hid as many gifts as she could fit in the closet\#and Peter stuffed into the stockings all the candy he could find. and Peter stuffed all the candy he could find into the stockings. $\#(221$

Reagan sent to his supporters many pleas for funds|Reagan sent many pleas for funds to his supporters\$and the Democrats sent to Congress an indictment of such practices.|and the Democrats sent an indictment of such practices to Congress. $\#(222$

The boss read to the newcomers the affirmative action law $\mid$ The boss read the affirmative action law to the newcomersfand the lawyer read to them the rules about false advertising. and the lawyer read the rules about false advertising to them.\#(2 23

Grandmother gave to my sisters all the family heirlooms|Grandmother gave all the family heirlooms to by sisters\#and grandfather gave to my brothers some valuable land in Texas. and grandfather gave some valuable land in Texas to my brothers. \#(2 24

Jim believed all Tom's stories were literally true|Jim believed all Tom's stories\#and Sue believed Jim's stories were fictitious.|and Sue believed Jim's stories.\#(3 25

The explorer knew the route to the Pacific Coast was difficult|The explorer knew the route to the Pacific Coast\#and his guides knew the route to South America was treacherous. |and his guides knew the route to South America.\#(3 26

Sally found out the solution to the physics problem was easy|Sally found out the solution to the physics problem\#and Ervin found out the solution to the math problem was trivial. and Ervin found out the solution to the math problem.\#(3 27

Johnny discovered the old basketball in the garage was deflated|Johnny discovered the old basketball in the garage\#and his mother discovered the rotting volleyball net was torn.|and his mother discovered the rotting volleyball net.\#(328

The newspaper reported atrocities in Asia were over|The newspaper reported atrocities in Asia\#and Amnesty International reported increased torture of prisoners in West Africa.|and Amnesty International reported increased torture of prisoners.\#(3 29

Tim guessed the terrorists' meeting place was in New York $\mid$ Tim guessed the terrorists' meeting place\#and the inspector guessed the location of their secret press was in Vermont.|and the inspector guessed the location of their secret press.\#(3 30

Friends in Washington heard the news about Reagan was true Friends in Washington heard the news about Reagan\#and other friends heard the rumor about the Russian defectors was true.|and other friends heard the rumor about the Russian defectors. \#(3 31

The spy saw the man with the strange umbrella poison Harold|The spy saw the man with the strange umbrella\#and the cop only saw the beautiful woman at the newsstand faint. and the cop only saw the beautiful woman at the newsstand.\#(3 32

Developers watched the construction of the skyscraper continue|Developers watched the construction of the skyscraper\#and the bankers watched the decay of nearby neighborhoods speed up.|and the bankers watched the decay of nearby neighborhoods.\#(333

The skiers felt the strong winds die down $\mid$ The skiers felt the strong winds\#and the instructor felt the rapidly dropping temperature stabilize.|and the instructor felt the rapidly dropping temperature.\#(3 34

The museum guide was signalling the girls should leave|The museum guide was signalling the girls\#and the security guard was signalling the guide should hurry. and the security guard was signalling the guide.\#(3 35

The clever boy realized the truth about the planet's age was not well understood|The clever boy realized the truth about the planet's age\#tand he realized the implications of this were gruesome. |and he realized the implications of this. \#(3 36

Jack rolled down the hill|The rock rolled down the hill\#and George did too, and the bucket did too.\#(4 37

The herons flew over the Atlantic|The airplane flew over the Atlantic\#and the gulls did too. land the satellite did too.\#(4 38

Nancy raced to the finish line|The car raced to the finish line\#and Tom did too.|and the motorcycle did too.\#(4 39

Bob floated down the river|The log floated down the river\#and Carol did too. |and the raft did too.\#(4 40

The kids crashed into the wall|The car crashed into the wall\#and the adults did too.|and the truck did too.\#(4 41

The saxophonist played softly|The saxophone played softly\#and the violinist did too. and the violin did too.\#(4 42

The bird hopped across the water|The pebble hopped across the water\#and the duck did too. and the stick did too.\#(4 43

Sally climbed to the top|The prices climbed to the top\#and John did too. and the Dow Jones Index did too.\#(4 44

The guests moved towards the window|The piano moved towards the window\#and the hostess did too. and the dining room table did too.\#(4 45

The beetle inched towards the fence|The compost pile inched towards the fence\#and the turtle did too. |and the cucumber plants did too.\#(4 46 The pilot landed on Macy's roof|The large red kite landed on Macy's roof\#and the pigeons did too. |and the balloons did too.\#(4 47

Your mother arrived last Monday/Your letter arrived last Monday \#and my uncle did too. and the packages did too.\#(4 48

John telephoned the doctor|John telephoned the library\#and his friend telephoned the lawyer.|and his friend telephoned the museum.\#(5 49

George stared at the reckless driver|George stared at the accident\#and Jane looked at him. land Jane looked at the sky. \#(5 50

Tommy kicked his brother|Tommy kicked the lamppost\#and Jane kicked the neighbor. Jand Jane kicked the fence.\#(5 51

The students liked the teachers|The students liked the textbooks\#and their parents liked the principal.|and their parents liked the films.\#(5 52 
Harold blamed the traffic cop|Harold blamed the bumpy road\#and his wife blamed the slow drivers.|and his wife blamed the bad weather.\#(5 53 The businessmen always discussed the politicians|The businessmen always discussed the economy\#and the lawyers always discussed the judges. |and the lawyers always discussed the legal system.\#(5 54

The grocer received some strange packages|The warehouse received some strange packages\#and the tailor did too.|and the shipping house did too. $\# 55$

My aunt survived the radical change in conditions|My violets survived the radical change in conditions\#and Henry did too.|and the orchids did too.\#(5 56

Karen underwent a lot of changes|The hospital underwent a lot of changes\#and Sally did too.|and the pharmacy did too.\#(5 57

Somehow the scientists withstood the severe weather|Somehow the flower garden withstood the severe weather\#and the news reporters did too.|and the vegetable garden did too.\#(5 58

The old doctor seemed to shrivel in winter|The old oak seemed to shrivel in winter\#and my relatives did too. and my rose bushes did too.\#(5 59 The animals played on the grass|The sun played on the grass\#and the children did too. land the breeze did too. $\# 60$

Note-The symbol $\mid$ divides the alternate forms of a pair of structural forms, and the symbol \# demarcates the conjuncts as they were presented in the experiment. The final number is the sentence number, and the number before that is the conditions number, where $1=$ passive vs. active, $2=$ heavy NP shifted $v s$. unshifted, $3=$ nonminimal vs. minimal attachment, $4=$ agent vs. theme, and $5=$ animate vs. inanimate.

(Manuscript received July 28, 1983;

revision accepted for publication March 29, 1984.) 